удК 130.12:130.2

DOI: 10.18101/1994-0866-2020-3-21-29

\title{
РЕЛИГИЯ КАК ЧЕТВЕРТАЯ ПОДСИСТЕМА КУЛЬТУРЫ (на примере мировых религий)
}

\author{
(C) Фёдоров Михаил Александрович \\ кандидат философских наук, доцент, \\ Бурятский государственный университет имени Доржи Банзарова \\ Россия, 670000, г. Улан-Удэ, ул. Смолина, 24а \\ fma1105@gmail.com
}

\begin{abstract}
Аннотация. Религия рассматривается как автономная подсистема культуры, наряду с природно-экологической, общественно-экологической и социорегулятивной подсистемами. Автором предлагается определение религии как системы идеальных и материальных средств деятельности, направленных на адаптацию к нематериальному миру, т. е. установление и регуляцию взаимоотношений человека с этим миром. В статье проанализированы концепции о происхождении и сущности религии. В качестве примера рассматриваются религиозные картины мира, предлагаемые христианством, исламом и буддизмом, а также наборы религиозных практик, детерминированные ими. В статье сделан вывод, что адаптация как основная функции религии подчеркивает примат идеального в рассмотрении религии, указывает на плюрализм религиозных картин мира, избегает оценочных категорий и исходит из требования принципов необходимости и достаточности в рассмотрении религиозных практик.
\end{abstract}

Ключевые слова: религия; происхождение религии; сущность религии; культура; адаптация; христианство; ислам; буддизм.

\section{Для цитирования}

Фёдоров М. А. Религия как четвертая подсистема культуры (на примере мировых религий) // Вестник Бурятского государственного университета. Философия. 2020. Вып. 3. С. 21-29.

Вопрос о происхождении и сущности религии является одним из самых многоаспектных и в то же время малодискуссионных, поскольку позиции мыслителей по этому вопросу в своем основании выражают не столько продукт рассуждения, сколько пример личного убеждения, где самый большой водораздел проходит по вопросу о бытии Бога - является ли Он источником откровения или продуктом человеческой мысли.

Ю. В. Гаврилова отмечает, что данный антагонизм проявляется уже в Греции в V в. до н. э., получая выражение в критике мифологии, возникшей в рамках обострения идеологической борьбы [9, с. 125]. Данная подоплека не исчезает и в эпоху Возрождения, и в Новое время, когда вопрос о происхождении религии был напрямую связан с вопросом о роли церкви и действенности моральных ограничений, налагаемых религиозными нормами.

Достаточно широкий диапазон материалистических концепций о причинах возникновения религии - страх перед неизвестным, невежество в естественнонаучных вопросах, необходимость в средствах социальной организации, игра во- 
ображения и т. д. - объясняется тем, что при исключении вмешательства духовного мира остается только человек и его деятельность. Нельзя не признать удачным возражение П. Д. Юркевича против эмпирических причин религии, как не только исключающих сверхъестественное из картины мира, но и низводящих человека до животного, в душе которого нет корней нравственных и религиозных явлений, имеющихся в его истории [цит. по: 23, с. 180].

Наибольший диапазон концепций сверхъестественного возникновения религии можно встретить у представителей русской духовно-академической мысли ХІХ в. - Ф. А. Голубинского, С. С. Гогоцкого, В. И. Несмелов, В. Д. Кудрявцева - Платонова и П. Д. Юркевича: врожденность идеи о Боге, божественное откровение и способность к восприятию сверхчувственного, целесообразный взгляд на мир, возвышающий человека от эгоистических стремлений до религиозного миросозерцания, образ Божий, отраженный в личности человека [цит. по 23, с. 173-181]. Давая детальную разработку этих концепций, мыслители, в рамках задач своего времени, остаются на монорелигиозной позиции, оценивая другие верования в контексте оппозиции истинного и не истинного, что могло являться одной из причин, по которой наследие этих мыслителей незаслуженно мало используется в религиоведении.

На современном этапе, как отмечает Ю. В. Гаврилова, российские религиоведы М. М. Шахнович и И. Н. Яблоков предпочитают говорить о комплексе факторов и предпосылок, способствующих возникновению и развитию религии, природных, социумных, антропных, социокультурных, психологических гносеологических $[9$, с. 130], что, с одной стороны, делает более гибкой аргументацию в применении к истории конкретной религии, а с другой - предлагает плюралистический консенсус в рамках материалистической парадигмы.

Более убедительной нам кажется позиция В. Ф. Мустафина, который приближается к вопросу о происхождении и сущности религии, последовательно противопоставляя религиозную веру таким феноменам, как знание, метафизика, воля, чувство, приходит к выводу, что они, как по отдельности, так и представленные совокупно, лишь сопровождают религиозную веру, но не составляют ее. Указывая на функцию веры в обеспечении средствами приспособления к действительности, исследователь ограничивает ее моделированием будущего и не развивает как базовую для понимания религии [17, с. 67-88].

Считаем, что наиболее продуктивно вопрос о происхождении и сущности религии можно представить с позиции религии как одной из подсистем культуры, которая позволяет дать непротиворечивое объяснение, не ограничиваемое условностями теизма, деизма или пантеизма. В рамках деятельностной концепции Э. С. Маркаряна и М. С. Кагана культура определяется как способ человеческой деятельности, позволяющий выживать человеку, «пасынку природы» по удачному выражению Н. Ф. Федорова, в самых разнообразных условиях. Адаптация как основной приспособительный результат культуры определяет следующие ее функции - обеспечение общества всем необходимым для выживания и обеспечение эффективности всех культурных механизмов [16, с. 62].

Э. С. Маркарян и М. С. Каган выделяют два направления адаптации - взаимодействие социальной системы с внешней средой и упорядочение целостности 
самой социальной системы [11, с. 47; 16, с. 63]. Внешняя среда, во-первых, включает биофизическое окружение, адаптация к которому предполагает наличие знаний, навыков, умений, орудий труда и предметов быта. Эти составляющие объединены в природно-экологическую подсистему культуры как ее элементы со статусом средств деятельности, и их состав детерминируется конкретными условиями проживания общества.

Во-вторых, внешняя среда в данной трактовке включает в себя другие сообщества, являющиеся носителями иных способов деятельности, разность которых делает необходимым выработку качественно особых регулятивных средств, обеспечивающих их взаимодействие, объединенных в общественно-экологическую подсистему культуры. Мы выделяем три стратегии взаимодействия культурных сообществ - противостояние, миграцию и дипломатию. Следование указанным направлениям зависит как от возможностей самого общества, так и от характера субъектов межкультурного взаимодействия.

Э. С. Маркарян также выделяет социорегулятивную подсистему культуры, включающую средства деятельности, создающие возможности для осуществления организации и координации усилий действующих индивидов и, следовательно, повышения упорядоченности и эффективности данного общества. Элементы данной подсистемы реализуют такие функции, как инкультурация, стимулирование и координация совместной деятельности, накопление и передача социально значимого опыта.

В числе прочих элементов данной подсистемы называется и религия, которая в рамках парадигмы диалектического материализма определяется либо как фантастическое отражение человеческого бытия, либо как одна из сфер, содержащих продукты духовного производства [16, с. 64-68, 137, 180], что ставит религию в один ряд с такими сферами человеческой деятельности, как искусство, наука или право.

Как следствие, функции религии рассматривают с точки зрения социального аспекта, выделяя мировоззренческую, компенсаторную, регулятивную, коммуникативную, интегрирующую, культуротранслирующую, легитимирующую, социализирующую, эйфорическую, социальной динамики, политическую $[19$, с. $331-$ $332 ; 21$, с. 596-602; 1, с. 150; 8, с. 76]. Однако определение сущности религий через призму этих функций, на наш взгляд, неприемлемо по нескольким причинам.

Во-первых, подобные функции приписываются другим элементам социокультурной подсистемы, например языку или искусству, которые очевидно являются не конкурирующими, а в лучшем случае взаимодополняющими феноменами. Во-вторых, все перечисленные функции не касаются сущности религиозной деятельности, а только описывают ее социальный эффект. Редукция религия к социально-действенным функциям понятна и оправдана в рамках материалистической парадигмы, однако содержание религии не просто указывает на существование идеальной реальности, а декларирует ее превосходство.

И наконец, указанные функции носят второстепенный характер, получая реализацию «попутно», тогда как содержание религии - ее вероучение и практики - указывает на сверхчувственный или духовный мир. Религиозное сознание принципиально отрицает опыт как единственный источник формирования знаний 
о мире, противопоставляя ему откровение как сумму знаний о метафизической реальности. Откровение как бы дорисовывает видимый мир, создавая обобщенную картину мира, в которой духовное и материальное объединено причинно-следственными связями.

Наша гипотеза состоит в том, что религия является четвертой подсистемой культуры, для которой мы считаем возможным предложить следующее определение: религия - это система идеальных и материальных средств деятельности, направленных на адаптацию к духовному миру. Причем разделение на материальное и идеальное в контексте семиотичности культуры достаточно условно: православный крест — не только элемент богослужебной практики, но и репрезентация основных христианских догматов, равным образом коллективность и регламентированность такого идеального элемента, как религиозная картина мира, предполагает ее представленность в религиозном дискурсе.

Адаптацию мы рассматриваем как базовую функцию религии - ее суть заключается в установлении и регуляции взаимоотношений человека с духовным миром. К необходимым компонентам религии мы относим религиозную картину мира, представляющую собой знание - откровение о содержании и характере духовного мира, определение человека и диапазон его статусов, детерминированных направлениями его деятельности, и сумма практик, направленных на адаптацию к описываемому духовному миру. Религиозное знание указывает на существование духовного мира, с которым человек вынужден взаимодействовать, предлагая способ и средства, направленных на поддержание своего статуса или его оптимизацию.

Важной характеристикой картины мира, предлагаемой мировыми религиями, является ее проблемность: откровение сообщает человеку знание не только о причине и способе появления мира, но и о причине его неустроенности. Например, христианское вероучение указывает, что начало миру положил Бог, сотворив Вселенную и все, что в ней, сделав это совершенным «увидел Бог все, что Он создал, и вот, хорошо весьма» [4, Быт 1:31] $]^{1}$. Совершенство творения было нарушено по причине греха - сознательного неподчинения человека божественной заповеди, следствием явилось нарушение гармонии в мире, приход болезни, страданий и смерти.

Грех понимается не только как вселенская катастрофа, последствия которой распространились на все человечество, но и как испорченность, не позволяющая реализовать идеалы, заложенные в человеке, изложенное ап. Павлом в виде дилеммы «Доброго, которого хочу, не делаю, а злое, которого не хочу, делаю» [4, Рим.7:19], абсолютное преодоление которой невозможно.

Таким образом, человек, созданный по образу Бога, т. е. обладающий разумностью, бессмертной душей, свободой воли и творчеством [10, с. 305, 307], вместо предназначенного ему уподобления Богу в любви называется мертвым по причине нарушения заповедей [4, Еф. 2:1-8]. Смерть понимается и как неспособность реализации религиозных идеалов, и как наказание, ожидающее человека. Более того,

1 Здесь и далее при ссылки на Библию используется традиционная система цитирования, указывающая название книга, номер главы и стиха. Расшифровка сокращений названий книг имеется в указанном издании. 
весь мир после грехопадения объявляется непригодным для человека и также подлежит уничтожению в конце своей истории.

Христианство как религия, т. е. связь с невидимым, начинается с Евангелия - радостной вести, в которой говорится об искуплении человека Богом и освобождении от власти греха. Человек, принимая верой основные положения, представленные в Никео-Цареградском символе веры, встает на путь перехода из сферы греховного мира в сферу царства Бога. Этот переход начинается с «рождения свыше» [4, Ин 3:5-7], который представлен в таинстве крещения - человек умирает для себя, чтобы жить для Бога [4, Гал 2:20].

В христианском вероучении подчеркивается необходимость благодати божественного действия, направленного на преодоление старой природы и вживание в новую [10, с. 454; 12, с. 119]. В Библии подчеркивается, что основанием новой жизни является не сумма убеждений, а сверхъестественное действие благодати [4, 1 Кор 2:1-5], происходящее в ответ на направленность верующего к Богу, выражаемую в молитве и культовых практиках.

Суть адаптивных практик можно выразить в приобретении веры, ее росте и совершенствовании: действие, направленная на реализацию религиозных идеалов, способствует усилению веры [4, Иак 2:18-26], недеяние - ее крушению. Конфессиональное разнообразие христианства стало причиной диверсификации понимания роли деятельности в Спасении: от необходимости духовного подвига в православии и католицизме до неизбежности дел веры в лютеранстве. Цель религиозной практики состоит в воссоединении с Богом в Его царстве и уподоблении богочеловеку Христу в любви и свободе от страстей.

Космология ислама основана на иудаистской и христианской традициях, претендуя на то, что именно здесь дано истинное откровение Аллаха, единого и всемогущего творца мира. Небо, духовный мир, состоит из сфер, включающих джанна (рай) - место упокоения праведников, и джаханнам (ад) - место наказание грешников. Населяют духовный мир ангелы, различающиеся по иерархии, архангелы, хранители человека, хранители могил, посланцы Аллаха и стражи рая и ада. Их противниками являются шайтаны - силы зла, предводительствуемые падшим ангелом Иблисом.

Основателем ислама является пророк Мухаммад, рассматриваемый как последний из божественных посланников в длинной череде, в которой встречаются герои Ветхого и Нового Завета. Свою роль Мухаммад видел в том, чтобы передать людям божественное откровение - Коран и восстановить истинную веру: «Он простил грехи и исправил положение тех, которые уверовали, совершали праведные деяния и уверовали в истину, ниспосланную Мухаммаду от их Господа» [20, $47: 2]^{1}$.

Коран, рассматриваемый как истинное откровение Аллаха, написан на арабском языке и находится в верхней из небесных сфер. Согласно вероучению ислама, Мухаммад получил откровение через посредство ангела Джебраила. Из этого следует обязательность использования в культовой практике только арабского текста, тогда как на других языках возможно только толкование арабского текста.

1 Здесь и далее при ссылке на Коран используется система цитирования, указывающая номер суры и аята. 
Мусульмане верят в предопределенность всех событий, которые своей конечной причиной имеют волю Аллаха. В этой связи человек должен полностью повиноваться воле Аллаха, потому что в конце его ожидает страшный суд, на котором испытаны их добрые дела «Те, чья чаша Весов окажется тяжелой, обретут успех. А те, чья чаша Весов окажется легкой, потеряют самих себя и вечно пребудут в Геенне» [20, 23; с.102-103].

Исламский культ обычно представляется как пять столпов веры: мусульманин должен исповедать свою веру, трижды произнеся шахаду, молиться пять раз в день, поститься в месяц Рамадан, платить налог в пользу бедных и совершить паломничество в Мекку. К шестому столпу относят джихад - борьбу за веру: изначально понимаемый как борьба против неверных, сейчас он представлен в виде разных форм, включающих также нравственное и социальное совершенствование [19, c. 292-301; 15, c. 436-443].

В суре Аль-Муминун (верующие) помимо этих практик перечисляются воздержание от прелюбодеяния и верность своим обязанностям. Следующие этим предписаниям верующие называются «преуспевшими» и «наследниками райских садов», где они смогут пребывать вечно [20, 23:1-11]. Перечисленные адаптивные практики - вера и праведные деяния - нацелены на то, чтобы следовать воле Аллаха и укреплять веру в догматы, предлагаемые Кораном, что вполне отражает значение названия религии - «покорность».

Космология буддизма метафорична: описание сфер духовных миров и сферы чувственного дано не для навигации, а указания на плененность человека в колесе сансары - совокупности движущихся и изменяющихся миров, по которым в процессе перерождения движется человек. В круге перерождений состояния блаженства противопоставлены адским мучениям, а активная деятельность- призракоподобному существованию [13].

Материальный мир описывается как совокупность дхарм, квантов знания, из которых состоят люди и другие живые существа. Подвижность и мгновенность дхарм подчеркивают иллюзорность мира: соединяясь, дхармы образуют состояние, называемое жизнью. Упокоение дхарм возможно при выходе из круга перерождений. В буддизме неустроенность мира выражена в цепи причинности (12 нидан), определяющей омраченность и невежество причиной страдания человека. Диагностируя порочность и иллюзорность мира, буддизм предлагает выйти за пределы круга перерождений при помощи знания четырех благородных истин и восьми ступеней, ведущих к великой истине. Конечной целью является нирвана сверхбытие, состояние покоя и свободы от страдания [14, с. 261-264].

Познание как следование восьми ступеням носит деятельностный характер: от буддиста требуется не только убежденность в их истинности, но и их реализация в повседневной жизни, где правильное воззрение реализуется в правильной решимости, правильной речи, правильном поведении, правильном образе жизни, правильном усилии и правильном направлении мысли. Следование этим ступеням помогает буддисту пройти четыре стадии правильного сосредоточения - от чистого мышления и покоя отрешенности от земного к состоянию невозмутимости, безразличия и самообладания [7]. 
Наилучшим путем для освобождения является монашество, поскольку жизнь в миру имеет много препятствий: различается три вида личности - низшая, заботящаяся о собственном благополучии в сансаре, средняя, стремящаяся к собственной нирване, и высшая, желающая покончить со страданиями других ценой собственных. Если первая личность может надеяться на улучшение своей кармы и лучшее перерождение, то высшая позволяет не только самому подвижнику избавиться от сансары, но и помочь другим. Архат - святой, достигший личного освобождения, может продолжить пусть просветления, достигнув бодхичитты, устремленности к просветлению для блага других [2, с. 57-58; 3, с. 5-6].

Страдание как квинтэссенция материального существования в буддийской картине мира делает оптимальным отрешение от связей с миром эмпирии и выход за его пределы. Адаптивные практики направлены на приобретение иммунитета от любого рода ментальных и чувственных привязанностей.

Как можно увидеть из приведенных примеров, каждая религия предлагает собственную версию картины мира: экуменический синтез невозможен и неуместен, поскольку любая религия, отстаивая себя, непременно либо частично, либо полностью отрицает другие. Христианское «никто не приходит к Отцу, как только через Меня» [4, Ин 14:16] или исламское «Повинуйтесь Аллаху, повинуйтесь Посланнику и не делайте тщетными ваши деяния» [20, 47:33] надо рассматривать не как религиозную ксенофобию, а как догматическую принципиальность.

Равным образом учение о пустоте (шуньята), отрицающее реальность мира [22], и учение бессамостности (анатма), отрицающее существование целостной и постоянной души [18, с. 19], является не коррекцией других религиозных традиций, а элементами автономной картины мира, обусловливающими направленность адаптивной деятельности человека.

Приведенные примеры подтверждают концепцию о том, что религия есть сумма адаптивных практик, детерминированных определенной картиной мира, раскрывающих содержание духовного мира и характер его влияния на человека. Вариативность религиозных картин мира, наиболее ярко представленная в мировых религиях, позволяет им согласиться в одном, что религия и ее нормы оказывают активное влияние на жизнь человека, что требует определенной суммы практик, направленных на оптимальное с ним взаимодействие.

Адаптация как основная функция религии позволяет ее рассматривать как одну из подсистем культуры, которую по классификации, предложенной Э. С. Маркаряном, можно назвать четвертой, хотя по значимости она должна являться первой, поскольку религия как сфера деятельности, декларирующая примат идеального, рассматривает деятельность человека, направленную на взаимодействие с природой, самоорганизацию или взаимодействие между коллективами, как подчиненную первой.

Определение адаптации как основной функции религии предлагает оптимальное взаимодействие между идеалистической и материалистической парадигмами мышления. С одной стороны, подчеркивается реальность метафизического, что является наиболее аутентичной стратегией в исследовании религии, с другой - допускает плюрализм религиозных картин мира, избегая оценочных кате- 
горий, и исходит из требования принципов необходимости и достаточности в рассмотрении религиозных практик, что соответствует принципу научной достоверности.

\section{Литература}

1. Аликберов А. К. Исторические изменения социальных функций религии (индивидуальный аспект) // Ислам в современном мире: внутригосударственный и международно-политический аспекты. 2017. Т. 13, № 1. С. 147-165.

2. Бадмаева М. В., Сандакова А. В. Практики преобразования ума и поведения бодхисаттв как отличительная черта буддизма махаяны // Вестник Бурятского государственного университета. 2018. № 3-2. С. 56-61.

3. Бадмацыренов Т. Б. Буддийская практика спасения в теории ступеней пути пробуждения // Вестник Бурятского государственного университета. 2015. № 14. С. 3-8.

4. Библия. Книги Священного Писания Ветхого и Нового Заветов. М.: Российское библейское общество, 2016. 1296 с.

5. Бодхипатхапрадипа. Светоч на пути к Пробуждению https://www.oum.ru/literature/buddizm/svetoch-na-puti-k-probujdeniu/ (дата обращения: 14.09.2020).

6. Буддийская космология // Мир Будды: интернет-портал. 2012-2020. URL: http://www.tamqui.com/buddhaworld/Буддийская_космология (дата обращения: 14.09.2020).

7. Восьмеричный путь // Мир Будды: интернет-портал. 2012-2020. URL: http://www.tamqui.com/buddhaworld/Восьмеричный_Путь (дата обращения: 14.09.2020).

8. Гаврилова Ю. В. Формирование философских представлений о социальных функциях религии // Гуманитарный вектор. 2009. № 3. С. 76-86.

9. Гаврилова Ю. В. Историко-философский анализ проблемы возникновения религии // Гуманитарный вектор. Серия: Педагогика, психология. 2010. URL: https://cyberleninka.ru/article/n/istoriko-filosofskiy-analiz-problemy-vozniknoveniya-religii (дата обращения: 18.09.2020).

10. Давыденков О., прот. Догматическое богословие: учеб. пособие. М.: Изд-во ПСГТУ, 2015. 624 с.

11. Каган М. С. Философия культуры. СПб.: Петрополис, 1996. 416 с.

12. Катехизис католической церкви. Компендиум / Культурный центр «Духовная библиотека», 2007. URL: www.vatican.va/archive/documents/archive_compendium-ccc ru.pdf (дата обращения: 13.09.2020).

13. Колесо Сансары // Мир Будды: интернет-портал. 2012-2020. URL: http://www.tamqui.com/buddhaworld/Колесо_Сансары (дата обращения: 14.09.2020).

14. Кульганек И. В. Буддизм // Религиоведение: учеб. пособие. 4-е изд., испр. и доп. СПб.: Лань, 2003. С. 255-280.

15. Любомиров Д. Е. Ислам // Религиоведение: учеб. пособие. 4-е изд., испр. и доп. СПб.: Лань, 2003. С. 431-455.

16. Маркарян Э. С. Теория культуры и современная наука. М.: Мысль, 1983. 279 с.

17. Мустафин В. Ф Философия религии // Религиоведение: учеб. пособие. 4-е изд., испр. и доп. СПб.: Лань, 2003. С. 66-89.

18. Нестеркин С. П. Основные тенденции развития буддизма в социокультурном пространстве России // Вестник Бурятского государственного университета. 2009. № 6. C. 16-20.

19. Религиоведение / под ред. М. М. Шахнович. СПб.: Питер, 2009. 432 с.

20. Священный Коран. URL: https://quran-online.ru/ (дата обращения: 14.09.2020).

21. Смагин Б. А. Социология религии // Религиоведение: учеб. пособие. 4-е изд., испр. и доп. СПб.: Лань, 2003. С. 580-603. 
22. Сутра сердца Праджняпарамиты / пер. Е. А. Торчинов // Введение в буддологию: курс лекций. СПб.: Санкт-Петербургское философское общество, 2000. С. 252-267. URL: http://anthropology.ru/ru/text/klassicheskie-teksty-drevniy-vostok/sutra-serdcapradzhnya- paramity (дата обращения: 12.09.2020).

23. Цвык И. В. Философская интерпретация сущности религии в русской духовноакадемической мысли XIX в. // Вестник РУДН. Серия: Философия. 2002. № 3. URL: https://cyberleninka.ru/article/n/filosofskaya-interpretatsiya-suschnosti-religii-v-russkoyduhovno-akademicheskoy-mysli-xix-v (дата обращения: 18.09.2020).

Статья поступила в редакиию 19.09.2020; одобрена после рецензирования 25.09.2020; принята к публикаџии 19..09.2020.

\section{RELIGION AS THE FOURTH SUBSYSTEM OF CULTURE}

(a study of world religions)

\section{Mikhail A. Fedorov}

Cand. Sci. (Philos.), A/Prof. of Religious Studies and Theology Department, Dorzhi Banzarov Buryat State University 24a Smolina St., Ulan-Ude 670000, Russia fma1105@gmail.com

Abstract. Religion is regarded as an autonomous subsystem of culture along with environmental, social and regulatory subsystems. We propose to define religion as a system of ideal and material means of human activity aimed at adaptation to the immaterial world, that is the establishment and regulation of interaction between human and the immaterial world.

As an example we have considered the religious worldview in Christianity, Islam and Buddhism, as well as a number of practices determined by these religions. It is concluded that adaptation as the main function of religion emphasizes the primacy of the idealism in religious studies, pluralism of religious worldview; avoids standards, and rely upon the principles of the necessity and sufficiency in studying religious practices.

Keywords: religion; the origin of religion; the nature of religion; culture; adaptation; Christianity; Islam; Buddhism. 